\title{
Characterization of Bespoke Force Sensors for Tailored Applications
}

\author{
Dafne Zuleima Morgado Ramirez, Maria del Pilar Garcia Souto, Benjamin M. Oldfrey, \\ Peter Smitham, Mark Miodownik, and Catherine Holloway
}

\begin{abstract}
Bespoke force sensors made with active polymer composites are inexpensive, thin and flexible, hence popular in wearable electronics, however their wider application is limited due to the lack of literature studying their voltage response related errors. We present the voltage response characterization of bespoke force sensors made with an active polymer composite, silver coated fabric, stainless steel thread, and silver epoxy. Characterization of the effects of static and dynamic loading was completed with a mechanical testing machine. Static tests consisted of loading and unloading at $0.01,0.1,0.5$ and $1 \mathrm{~N} / \mathrm{s}$, and drift tests for 120 minutes up to $10 \mathrm{~N}$ every $1 \mathrm{~N}$. Dynamic tests consisted of a sinusoidal load of $5 \mathrm{~N} \pm 1 \mathrm{~N}$ applied at $0.05,0.1$, and $0.5 \mathrm{~Hz}$ for $60 \mathrm{~min}$. The force-voltage relationships were modeled using an exponential function. Maximum mean drift error was observed when applying different static loads for 120 minutes each. Drift error is minimal at $5 \mathrm{~s}(<1 \%)$ and at $60 \mathrm{~min}$ $(<5 \%)$ with loads under $1 \mathrm{~N}$. Maximum hysteresis of $18 \%$ was observed at the $1 \mathrm{~N} / \mathrm{s}$ loading rate. The maximum drift error after $1 \mathrm{~h}$ of dynamic loading was observed at $0.5 \mathrm{~Hz}$ and is minimal $(-0.00004 \%)$. The cost of fabricating these sensors is very low compared with commercially available options. These sensors can be fabricated in any shape and size with the added advantage of being able to set the location of the electronic connections as desired.
\end{abstract}

Index Terms-Conductive materials testing, force sensors, instrumentation, transducers, wearable sensors.

\section{INTRODUCTION}

B ESPOKE electronics for force sensing are becoming increasingly popular and have been used in a wide variety of 'hack-type' projects [1], [2] as well as more formal wearable electronics experiments [3] and teaching [4]. There

Manuscript received October 26, 2016; accepted December 11, 2016. Date of publication December 22, 2016; date of current version February 17, 2017. This work was supported by the Engineering and Physical Sciences Research Council EPSRC under Grant EP/K020323/1. The associate editor coordinating the review of this paper and approving it for publication was Prof. Zeljko Ignjatovic.

D. Z. Morgado Ramirez and Catherine Holloway are with the UCLIC, University College London, London WC1E 6EA, U.K. (e-mail: d.morgadoramirez@ucl.ac.uk; c.holloway@ucl.ac.uk).

M. del P. Garcia Souto is with the Medical Physics and Biomedical Engineering Department, University College London, London WC1E 6BT, U.K. (e-mail: p.garciasouto@ucl.ac.uk).

B. M. Oldfrey is with the Centre for Mathematics, Physics and Engineering in the Life Sciences and Experimental Biology, University College London, London WC1E 6BT, U.K. (e-mail: benjamin.oldham.13@ucl.ac.uk).

P. Smitham is with the Institute of Orthopedics and Musculoskeletal Science, University College London, Stanmore HA7 4LP, U.K. (e-mail: petersmitham@gmail.com).

M. Miodownik is with the Mechanical Engineering Department, University College London, London WC1E 7JE, U.K. (e-mail: m.miodownik@ucl.ac.uk).

This paper has supplementary downloadable multimedia material available at http://ieeexplore.ieee.org provided by the authors. The Supplementary Material contains a video that demonstrates the making of a bespoke force sensor and a Word file that contains Appendix 1. This material is $275 \mathrm{MB}$ in size.

Digital Object Identifier 10.1109/JSEN.2016.2644378 have been a wide variety of applications and uses for such sensors. The simplest application uses sensors as simple binary switches, for example, light up LEDs [2]. More complex projects have created variable inputs to control a PC cursor or video game [2]. Other applications have shown the ability to create sensors with more complex geometries, opening up the possibility of sensors in any shape. For example a speaker with force sensors shaped into letters, which allows the user to drag their hand along the speaker to change the volume [2]. Recent applications have demonstrated the use of these sensors in monitoring human sitting posture [5], making human-robot interactions safer [6] and for enabling spinal cord injury patients to control devices through a sensor inside their hard palate [7].

These bespoke force sensors are made using one layer of active polymer composite such as carbon loaded polyolefin, commercially known as Velostat or Linqstat. The polymer composite is sandwiched between two electrodes, traditionally made of copper tape or aluminium foil, and insulated with adhesive tape or nonconductive fabric. The electrical characteristics of the active polymer composite are unaffected by aging and humidity, and has the advantage of being thin $(100 \mu \mathrm{m})$. Force sensors made with this material are not only easy to make but are also relatively inexpensive in comparison with commercially available alternatives.

Most current applications do not require a high level of precision in the sensor or the control. However, the application of such bespoke sensors could be expanded to more specialized applications if their measurement related errors were known.

Previous work has begun to model aspects which influence the resistive response and behavior of these low cost resistive force sensors. Initial studies investigated sensors made with one layer of polymer composite [8] and the effect of design changes on the voltage response, such as: more than one piezo resistive layer, various electrode configurations and different material compositions [9]. One study has evaluated force sensors made with elastic electrodes yet with a non-elastic piezo resistive layer [10]. Similarly, a study has investigated the repeatability, sensibility and range of these low cost resistive sensors while modifying the number of electrodes and piezo resistive layers [11]. The performance of commercially available thin and flexible sensors has been studied before [12]. However, there is no literature reporting the voltage response errors such as hysteresis and drift under static and dynamic tests for bespoke force sensors made with Velostat. This crucial information is fundamental to allow an informed force analysis in any experimental setting and also to allow comparisons between bespoke 


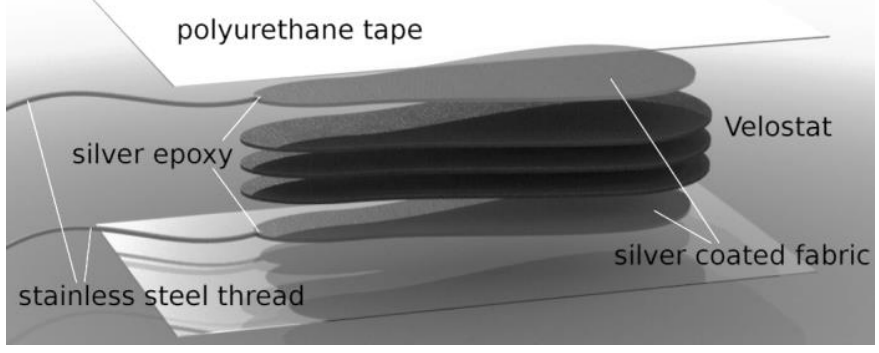

Fig. 1. Schematic of sensor components.

TABLE I

COMPARISON TABLE of CONDUCTIVE FABrics

\begin{tabular}{ccccc}
\hline Name & $\begin{array}{c}\text { Surface } \\
\text { resistivity } \\
(\boldsymbol{\Omega})\end{array}$ & $\begin{array}{c}\text { Thickness }^{\text {a }} \\
(\mathbf{m m})\end{array}$ & Fraying & $\begin{array}{c}\text { Very } \\
\text { flexible }\end{array}$ \\
\hline Bremen AB & $<1$ & 0.09 & yes & yes \\
Nora LX & $<0.05$ & 0.1 & no & no \\
Nanking & $<0.3$ & 0.1 & no & yes \\
Nora & $<0.03$ & 0.1 & yes & yes \\
Bremen IR & $<0.5$ & 0.09 & yes & yes \\
Bremen & $<0.5$ & 0.09 & yes & yes \\
Budapest & $<1$ & 0.15 & yes & yes \\
Zell & $<0.02$ & 0.1 & no & no \\
Zell CR & $<0.02$ & 0.13 & no & no \\
Nora Dell & $<0.009$ & 0.13 & no & no \\
\hline \multicolumn{5}{c}{ Reported by the manufacturer }
\end{tabular}

TABLE II

COMPARISON TABLE OF CONDUCTIVE THREADS AND YARNS

\begin{tabular}{ccccc}
\hline Name & $\begin{array}{c}\text { Resistance } \\
\text { at } \mathbf{1 3} \mathbf{~ c m} \\
(\Omega)\end{array}$ & Fraying & $\begin{array}{c}\text { Strong } \\
\text { weave }\end{array}$ & Thin \\
\hline 235/34 HC & 36.1 & yes & no & yes \\
44/13Z-100RD & 228.1 & yes & no & yes \\
44/13Ag+113/PES & $7.08 \mathrm{~K}$ & no & yes & yes \\
78/18Z-Turn & 359.9 & no & no & yes \\
22/1RD & $1.035 \mathrm{~K}$ & no & yes & yes \\
33/12 2 Turns+B & $1.208 \mathrm{M}$ & yes & yes & yes \\
SM1 INC 210 & 309.7 & no & yes & yes \\
235/34 dtex 2-ply & 34.1 & no & yes & yes \\
235/34 dtex 4ply & 10.8 & no & yes & no \\
Tex 92 & & no & yes & yes \\
640 2-ply & 4.7 & no & &
\end{tabular}

low-cost sensors and commercially available sensors [13]. This paper addresses this gap in the literature by reporting results of the characterization of the voltage response of bespoke force sensors made with active polymer composites and other carefully selected materials based on their conductivity and durability. We will also provide a fabrication and implementation guide of those bespoke force sensors.

\section{DESIGN AND FABRiCATION}

Three force sensors were manufactured with the materials shown in an example sensor in Fig. 1. All sensors were manufactured with the same materials, shape and area. The conductive fabric, thread and cold solder epoxy used for manufacturing the sensors were selected among a list of options (Table I) through a series of pilot studies. Ten different

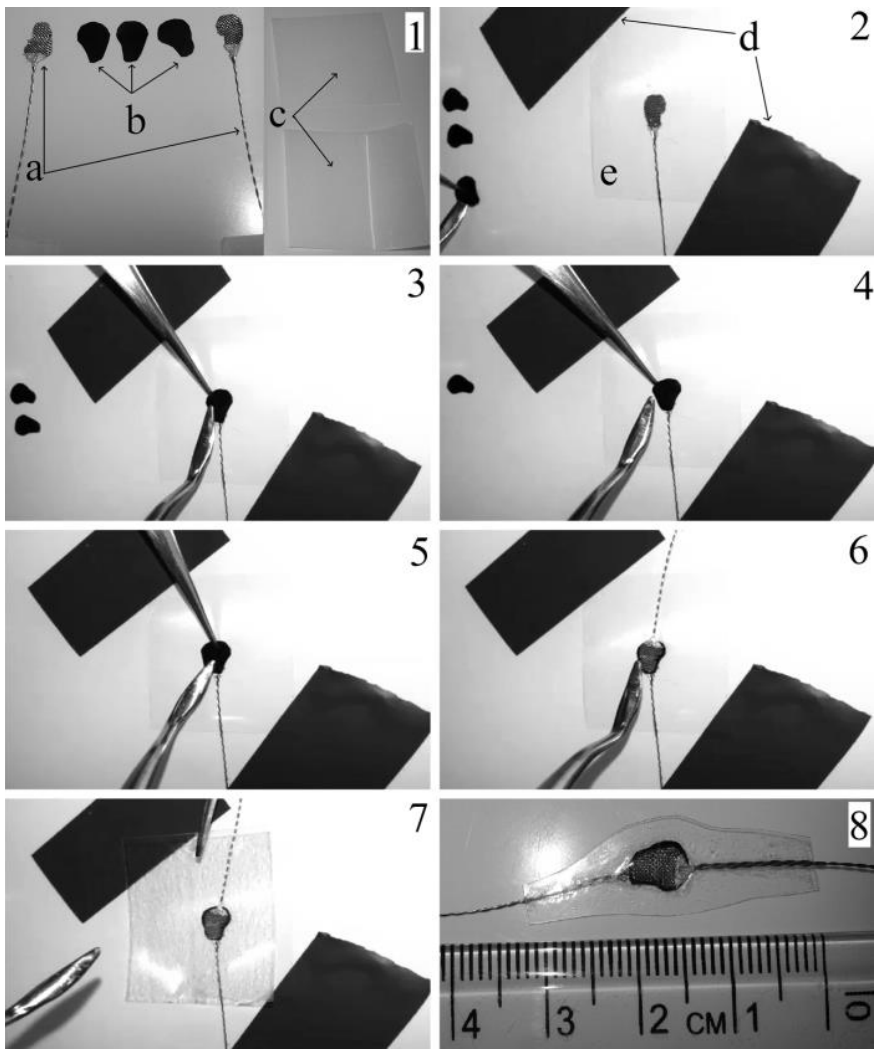

Fig. 2. Assembly stages of a force sensor. Components required are: two layers of conductive fabric glued with stainless steel thread $(1$, a), three layers of conductive polymer composite $(1, b)$, transparent permanent polyurethane adhesive tape $(1, \mathrm{c})$ and insulating tape to hold polyurethane tape in place $(2, \mathrm{~d}, \mathrm{e})$. Steps consist in: the cutting of the conductive fabric and polymer composite to desired shape $(1, a, b)$, placing of conductive fabric and glued thread over polyurethane tape with adhesive facing upwards $(2, \mathrm{e})$, polyurethane tape is held with insulating tape to a flat surface $(2, d)$ placing of polymer composite layers over first layer of conductive fabric, placing of three layers of conductive composite polymer over the first conductive fabric layer (3-5), a second conductive fabric with glued stainless steel thread is placed over previous parts (6), insulating all previous elements in place with polyurethane tape with adhesive facing downwards (7) and cutting of sensor sealing to desired shape (8).These photos were extracted from the video that accompanies this paper.

commercially available conductive fabrics that vary in thickness, surface resistivity and weave were assessed (Table I). Conductive thread was chosen for its durability, flexibility, and scale of the electrode in contrast with prefabricated electrode connections. A total of 11 commercially available yarns and threads were assessed: ten silver coated conductive polyamide yarns and threads (Statex Produktions \& Vertriebs $\mathrm{GmbH})$ and one stainless steel thread (Adafruit) (Table II). Conductive fabrics were chosen over copper tape $(0.15 \mathrm{~mm})$ and heavy aluminum foil $(0.07 \mathrm{~mm})$ as their thickness is similar $(0.09 \mathrm{~mm})$ and are flexible without breaking. Bremen fabrics were chosen due to their small thickness, flexibility and minimal fraying weaves. A stainless steel 2-ply thread was selected due to its low resistivity, strength and absence of fraying. Two commercially available silver based 2-part epoxy resins with equal volume resistivity of $0.0007 \Omega \mathrm{cm}$ were tested to cold solder the chosen thread to the conductive fabric electrodes: ElectroDag 5810 and MG Chemicals adhesive 8330S of mixing ratios $16: 1$ and 1:1 respectively. 8330S was chosen as it is easy to mix, cures at room temperature 


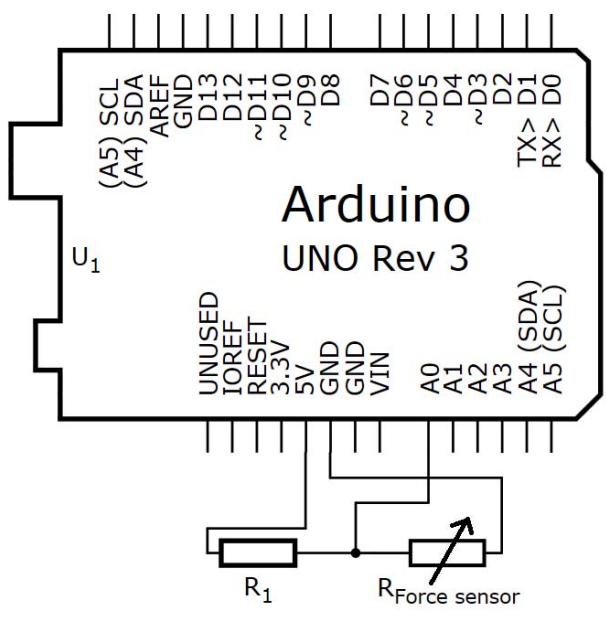

Fig. 3. Electronic circuit schematic used to power the force sensors with $5 \mathrm{~V}$ where $\mathrm{R}_{1}=100 \mathrm{k} \Omega$.

(96 hours at $25{ }^{\circ} \mathrm{C}$ or 2 hours at $65{ }^{\circ} \mathrm{C}$ ) and has a strong adhesion to steel.

The steps to assemble all parts of the sensor are detailed in Fig. 2 from step 2 to 7 . The order of the sensor parts can be seen in Fig. 1 and the final result in step 8, Fig. 2. In summary, the sensor manufacturing procedure followed was:

1) Two layers of conductive silver coated fabric were cut to the desired shape and size of the sensing area, we cut a circular shape.

2) A section of stainless steel thread was attached to each of the conductive fabric cuttings with a small drop of silver epoxy located at the edge (just enough to hold the two materials together, approximately $0.5 \mathrm{~mm}^{3}$ ) (step 1, a, Fig. 2).

3) Three polymer composite layers were cut with a $0.5 \mathrm{~mm}$ boundary to a circular sensing area of $12.56 \mathrm{~mm}^{2}$ (step 1, b, Fig. 2).

4) Once the silver epoxy had cured, all parts were assembled and insulated with a clear permanent polyester tape DYMO Rhino $24 \mathrm{~mm}$ wide (step 1, a, Fig. 2). The opposing conductive fabric cuttings did not touch each other once all parts were assembled.

In order to perform various mechanical tests, a steel indenter of equal area and shape to the circular sensing area of the sensors was used to load/unload the sensors via a mechanical testing machine (Instron Electropuls E3000, ITW Ltd.) with a $50 \mathrm{~N}$ load cell (Instron 2530-437, ITW Ltd.) which has a reported $10 \%$ drift and a $0.1 \%$ hysteresis. Force sensors were connected to a voltage divider fed with $5 \mathrm{~V}$ and simultaneous force and voltage measurements were taken (the voltage decreased with increasing force) (Fig. 3). Voltage data acquisition was performed by establishing a connection between an Arduino UNO board and a custom made program in LabVIEW (2013, National Instruments). Data analysis was performed with custom made scripts in Matlab (R2013b, Mathworks Inc.). Voltage and force data were acquired at $50 \mathrm{~Hz}$ and low pass filtered at $1 \mathrm{~Hz}$ with a zero phase $5^{\text {th }}$ order Butterworth algorithm and then resampled to $10 \mathrm{~Hz}$. Before data analysis, the absolute value of voltage $(V)$ data of each sensor was corrected for voltage offset (voltage read at zero loading of the sensor was subtracted, $V_{0}$ ) and then normalized by the maximum voltage read at the maximum force of $10 \mathrm{~N}\left(V_{\max }\right)$ applied during the characterization of each sensor, here onwards called normalized voltage $\left(V_{N}\right)$ as in

$$
V_{N}=\frac{V-V_{0}}{V_{\max }-V_{0}}
$$

Static (Fig. 4) and dynamic characterizations (sinusoidal loading at three different frequencies), explained in detail in the next section, were performed on the three sensors.

\section{STATIC Characterization}

\section{A. Force-Voltage Relationship}

Measurements were taken on the three sensors to establish the relationship between an applied force and the sensor voltage output. A force of 0 to $10 \mathrm{~N}$ was applied four times at four different rates $(0.01,0.1,0.5$ and $1 \mathrm{~N} / \mathrm{s})$ recording loading and unloading curves for force and voltage simultaneously (Fig. 4, tests A to D). These series of tests were performed in order to obtain data indicative of a broad range of testing conditions. Curve fitting was used to determine an exponential model of the force-voltage relationship (2) using the normalized voltage resulting in an coefficient of determination $\left(\mathrm{R}^{2}\right)$ of 0.8949 and root mean square error of 0.9608 as reported in Fig. 5.

$$
\text { Force }=a e^{6.788 V_{N}}+b e^{-0.6364 V_{N}}+c
$$

Where $a$ is $0.008507, b$ is -5.555 and $c$ is -5.532 . $\mathrm{R}^{2}$ is a measure of how well the exponential regression line approximates the real data points. When $\mathrm{R}^{2}$ has a value of 1 it indicates that the regression line perfectly fits the data.

\section{B. Drift Error With Static Loading}

Drift error was calculated as the change in the sensor voltage response to a constant static force. Ten static loads, from $1 \mathrm{~N}$ to $10 \mathrm{~N}$ in steps of $1 \mathrm{~N}$, were applied for 120 minutes each, with the loading and unloading between steps occurring at 0.01 $\mathrm{N} / \mathrm{s}$ (Fig. 4, test F). An example of the normalized voltage drift for a sensor can be seen in Fig. 6. Drift was reported as a percentage shift per time given (Fig. 7) as calculated in (3) where $t$ is time in seconds and $N$ is the total number of samples. Drift error was calculated at 5 s, 60 s, 3,600 s, and $7,200 \mathrm{~s}$.

$$
\begin{aligned}
& \text { Drift } \text { error }_{\text {static load }} \\
& =\left(\frac{\left(\frac{1}{N} \sum_{t-1}^{t} V_{N}\right)-\left(\frac{1}{N} \sum_{t=0}^{t=1} V_{N}\right)}{\frac{1}{N} \sum_{t=0}^{t=1} V_{N}}\right) 100
\end{aligned}
$$

\section{Hysteresis Error}

From the data obtained during the loading and unloading for the observation of the force and voltage relationship, hysteresis error was estimated using (4). Where $V_{N l}$ and $F_{l}$ are the normalized voltage and applied force during loading respectively whereas $V_{N u}$ and $F_{u}$ are the voltage and force 


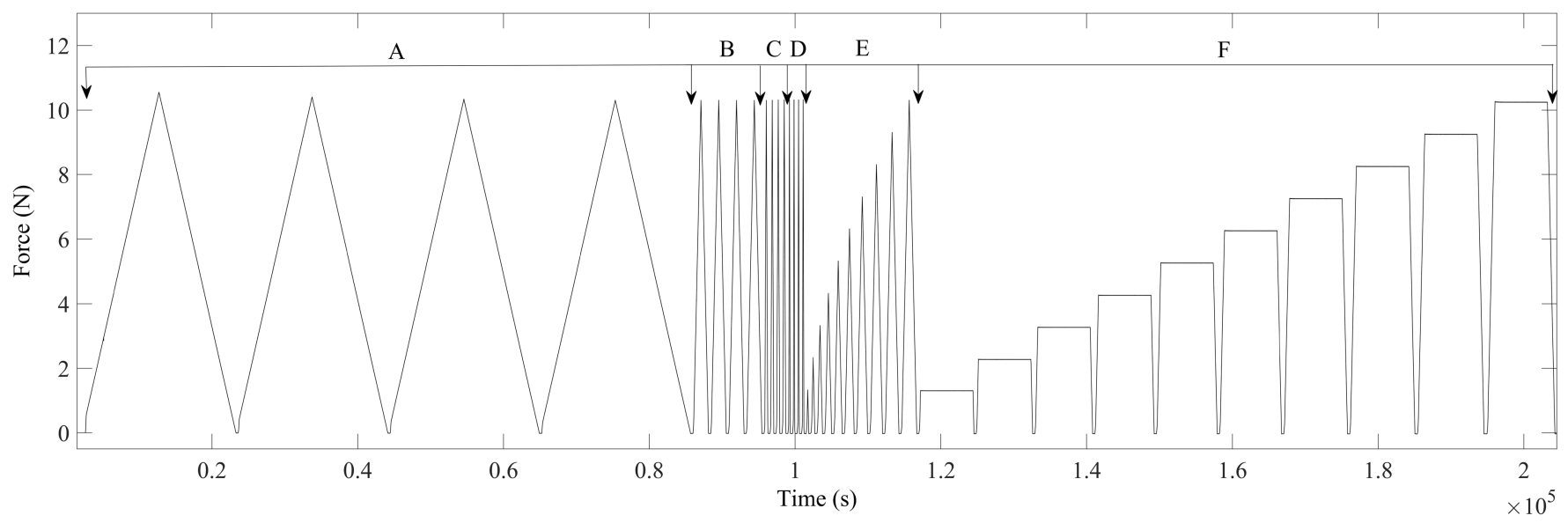

Fig. 4. Sample of static force tests performed. Loading and unloading repeated four times at four different force rates: $0.01 \mathrm{~N} / \mathrm{s}(\mathrm{A}), 0.1 \mathrm{~N} / \mathrm{s}(\mathrm{B}), 0.5 \mathrm{~N} / \mathrm{s}$ (C), $1 \mathrm{~N} / \mathrm{s}(\mathrm{D})$. Drift tests with a static force held for 120 minutes every $1 \mathrm{~N}$ while loading and unloading at $0.01 \mathrm{~N} / \mathrm{s}$ (F), and pre-drift tests consisting of loading and unloading at $0.01 \mathrm{~N} / \mathrm{s}$ every $1 \mathrm{~N}$ without holding a static force $(\mathrm{E})$.

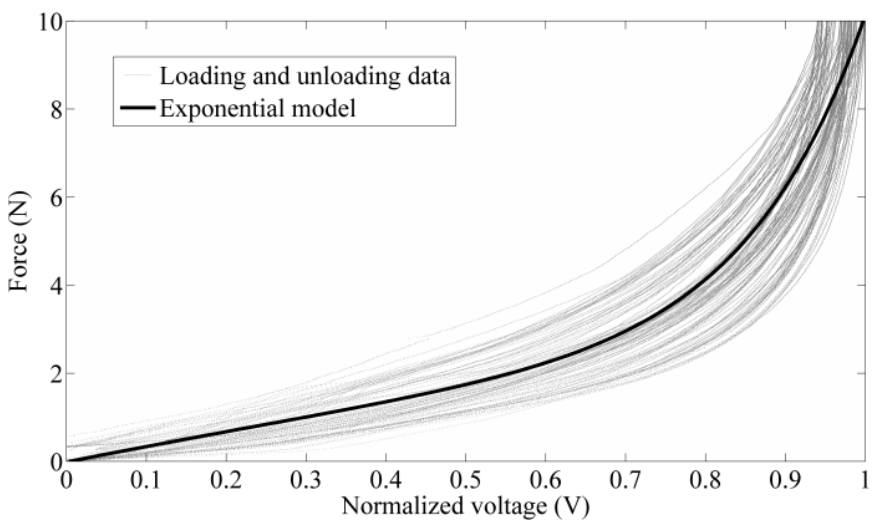

Fig. 5. Force-voltage relationship for three sensors made with the same materials and specifications. This relationship corresponds to load and unloading tests at four different speeds up to $10 \mathrm{~N}$. Recommended exponential model fitted. This model could be used as a calibration curve.

TABLE III

VoltAGE HySTERESIS ERROR (\%) FOR CONSECUTIVE LOADING AND UnloAding TeStS AT DifFERENT ForCe Rates

\begin{tabular}{ccccc}
\hline & \multicolumn{4}{c}{ Force rate (N/s) } \\
\cline { 2 - 5 } & $\mathbf{0 . 0 1}$ & $\mathbf{0 . 1}$ & $\mathbf{0 . 5}$ & $\mathbf{1}$ \\
\hline Mean (\%) & 14.040 & 12.969 & 16.523 & 18.030 \\
Standard deviation (\%) & 4.552 & 6.240 & 3.975 & 6.290 \\
\hline
\end{tabular}

during unloading of the sensors (4). Mean hysteresis values were obtained for all sensors and repetitions at each loading rate $(0.01,0.1,0.5$ and $1 \mathrm{~N} / \mathrm{s})$ (Table III).

$$
\text { Hysteresis error }=\left(\frac{\underset{F_{l}=F_{u}}{\max }\left|V_{N u}-V_{N l}\right|}{\max \left\{V_{N u}, V_{N l}\right\}}\right) 100
$$

\section{Effect of Drift Error on Hysteresis Error}

The experimental observations during the drift tests (Fig. 4, test F) present the combined effect of the hysteresis error due to the loading-unloading cycle and the drift error due to the static load held. In order to understand the effect of the drift error on hysteresis we have designed a test to separate these errors. A reference test where we knew that drift error was not present (Fig. 4, test E) was employed to compare it with

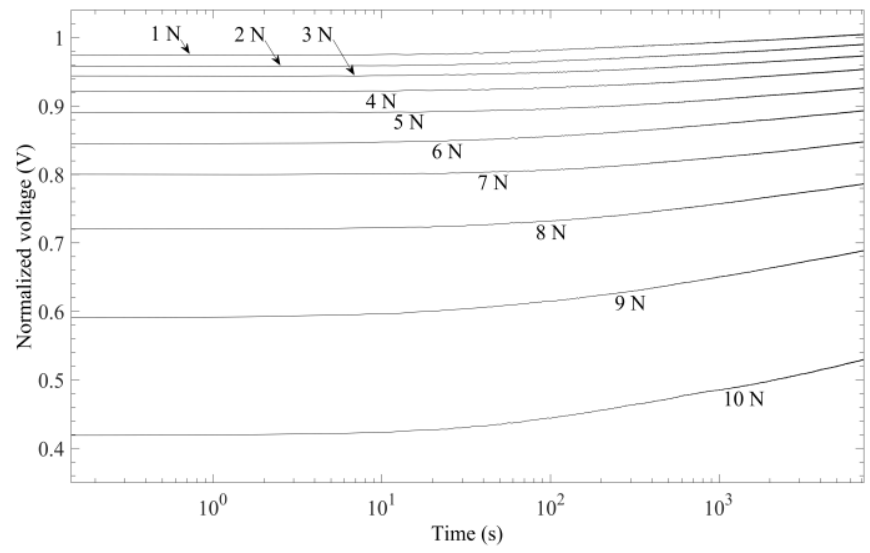

Fig. 6. Example of voltage drift every $1 \mathrm{~N}$ up until $10 \mathrm{~N}$ for a sensor.

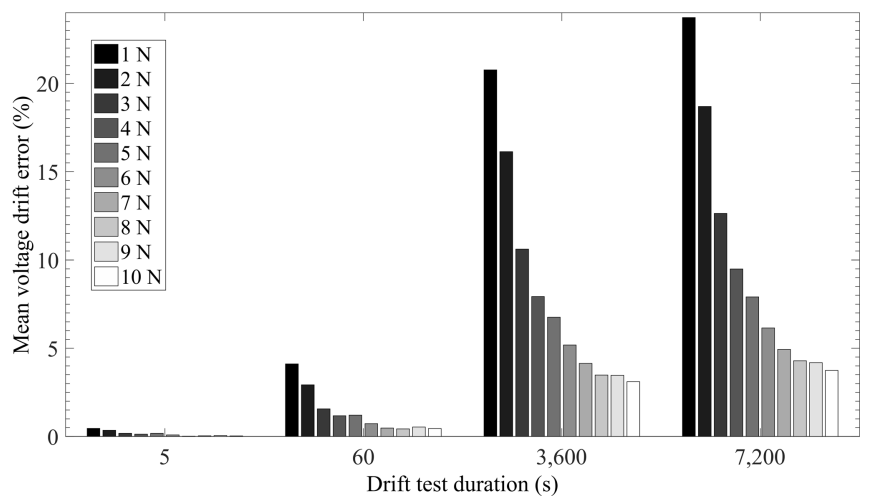

Fig. 7. Mean voltage drift error across all sensors for loading at every $1 \mathrm{~N}$ up until $10 \mathrm{~N}$.

a test where drift and hysteresis error were present (Fig. 4, test F). Loading and unloading at $0.01 \mathrm{~N} / \mathrm{s}$ from $1 \mathrm{~N}$ to $10 \mathrm{~N}$ in steps of $1 \mathrm{~N}$ (Fig. 4, test E) were applied to calculate what we called non-drift hysteresis. Separately, we calculated another hysteresis from the loading and unloading sections of the drift test with static loading (Fig. 4, test F). The latter is the hysteresis error calculated under the influence of the drift error that we call drift-hysteresis. If the non-drift hysteresis is compared with the drift-hysteresis, then the influence of 
TABLE IV

EFFect of Continuous Application of a Static Force ON VOLTAGE HySteresis ERROR (\%)

\begin{tabular}{cccc}
\hline $\begin{array}{c}\text { Force reached } \\
\text { during the loading- } \\
\text { unloading cycle (N) }\end{array}$ & $\begin{array}{c}\text { Voltage } \\
\text { hysteresis } \\
\text { without a } \\
\text { static force } \\
\mathbf{( \% )}\end{array}$ & $\begin{array}{c}\text { Voltage } \\
\text { hysteresis } \\
\text { with a static } \\
\text { force (\%) }\end{array}$ & Difference \\
\hline $\mathbf{1}$ & 27.479 & 24.158 & -3.321 \\
$\mathbf{2}$ & 17.971 & 18.296 & 0.325 \\
$\mathbf{3}$ & 12.029 & 28.260 & 16.231 \\
$\mathbf{4}$ & 9.980 & 33.118 & 23.138 \\
$\mathbf{5}$ & 13.681 & 29.800 & 16.118 \\
$\mathbf{6}$ & 10.765 & 25.063 & 14.298 \\
$\mathbf{7}$ & 11.377 & 20.843 & 9.467 \\
$\mathbf{8}$ & 8.291 & 19.996 & 11.705 \\
$\mathbf{9}$ & 10.291 & 19.820 & 9.529 \\
$\mathbf{1 0}$ & 8.375 & 19.482 & 11.108 \\
\hline
\end{tabular}

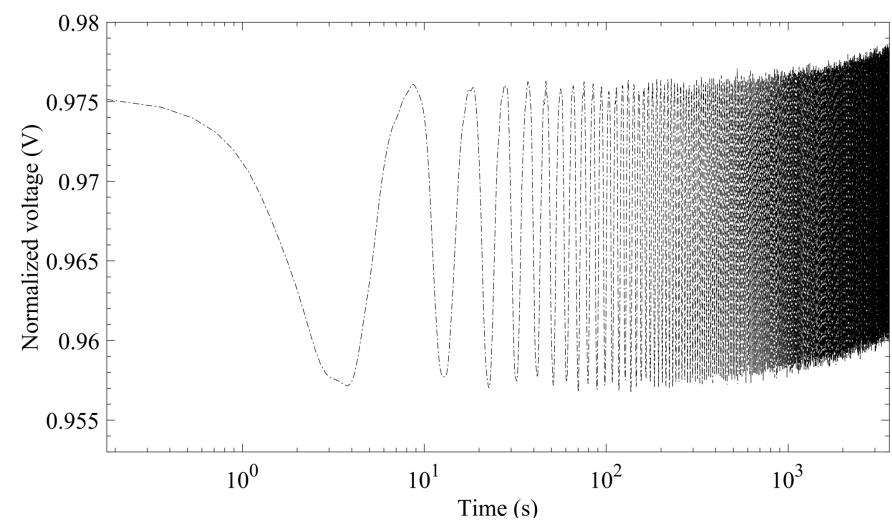

Fig. 8. Example of dynamic test at $0.1 \mathrm{~Hz}$ for a sensor.

drift error on hysteresis error can be determined. This was calculated as the difference between two hysteresis errors: one calculated from loading-unloading cycles at $0.01 \mathrm{~N} / \mathrm{s}$ without drift tests (Fig. 4, test E) and the other calculated from the loading-unloading cycles at $0.01 \mathrm{~N} / \mathrm{s}$ with drift tests (Fig. 4, test F) (Table IV). All hysteresis errors were calculated using (4).

\section{DYNAMIC CHARACTERIZATION}

\section{A. Force Response}

Sinusoidal loads with a peak to peak amplitude of $2 \mathrm{~N}$ oscillating around $5 \mathrm{~N}$ were applied at $0.05,0.1$ and $0.5 \mathrm{~Hz}$ for 60 minutes respectively (Fig. 8). Mean and standard deviation of the normalized voltage seen during this test was calculated (Table V).

\section{B. Drift Error With Dynamic Loading}

Drift error was calculated by determining the change in the mean normalized voltage from the first five seconds to the last five seconds of the 60 minutes test (Table V) as in

$$
\begin{aligned}
& \text { Drift error mean dynamic load }=\left(\frac{\left(\frac{1}{N} \sum_{t=3595}^{t=3600} V_{N}\right)-\left(\frac{1}{N} \sum_{t=0}^{t=5} V_{N}\right)}{\frac{1}{N} \sum_{t=0}^{t=5} V_{N}}\right) 100
\end{aligned}
$$

TABLE V

Voltage Mean, Voltage Standard Deviation and Voltage Drift ERRor (\%) AT 60 MinUtes of A DYNAMIC LOADING TEST AT THREE DIFFERENT FREQUENCIES

\begin{tabular}{cccc}
\hline & \multicolumn{3}{c}{ Frequency (Hz) } \\
\cline { 2 - 4 } & $\mathbf{0 . 0 5}$ & $\mathbf{0 . 1}$ & $\mathbf{0 . 5}$ \\
\hline $\begin{array}{c}\text { Mean Voltage } \\
\text { (V) }\end{array}$ & 0.949 & 0.948 & 0.951 \\
$\begin{array}{c}\text { Standard } \\
\text { deviation (V) }\end{array}$ & $9.960 \mathrm{E}-03$ & $9.493 \mathrm{E}-03$ & $7.699 \mathrm{E}-03$ \\
$\begin{array}{c}\text { Drift error on } \\
\text { mean V (\%) }\end{array}$ & $3.733 \mathrm{E}-05$ & $1.207 \mathrm{E}-04$ & $5.123 \mathrm{E}-05$ \\
$\begin{array}{c}\text { Drift error on } \\
\text { maximum V (\%) } \\
\text { Drift error on } \\
\text { minimum V (\%) }\end{array}$ & $4.094 \mathrm{E}-05$ & $5.781 \mathrm{E}-05$ & $3.527 \mathrm{E}-05$ \\
\hline
\end{tabular}

TABLE VI

COMPARISON OF CHARACTERISTICS BETWEen BEsPoke ForCE

\begin{tabular}{|c|c|c|c|}
\hline Characteristic & $\begin{array}{l}\text { Sensor in this } \\
\text { paper }\end{array}$ & $\begin{array}{c}\text { FSR Model } 400 \\
\text { (Interlink } \\
\text { Electronics } \\
\text { Inc.) }\end{array}$ & $\begin{array}{c}\text { Flexiforce } \\
\text { A101 } \\
\text { (Tekscan, Inc) }\end{array}$ \\
\hline $\begin{array}{l}\text { Sensing area } \\
\left(\mathrm{mm}^{2}\right)\end{array}$ & 12.56 & 20.26 & 11.34 \\
\hline Thickness (mm) & ${ }^{\mathrm{a}} 0.7$ & 0.3 & 0.203 \\
\hline $\begin{array}{l}\text { Electrode pin } \\
\text { spacing }\end{array}$ & Any desired & fixed & fixed \\
\hline $\begin{array}{l}\text { Non actuated } \\
\text { resistance }\end{array}$ & $>20 \mathrm{M} \Omega$ & $>10 \mathrm{M} \Omega$ & $>30 \mathrm{k} \Omega$ \\
\hline Hysteresis & $\begin{array}{c}15.39 \% \pm 5.56 \text { at } \\
\text { various load } \\
\text { rates }(0.01,0.1 \\
0.5 \text { and } 1 \mathrm{~N} / \mathrm{s})\end{array}$ & $10 \%$ average & $\begin{array}{l}4.5 \% \text { of full } \\
\text { scale }\end{array}$ \\
\hline Static drift & $\begin{array}{c}3.74 \% \pm 1.27 \text { at } \\
10 \mathrm{~N} \text { after } 2 \\
\text { hours }\end{array}$ & $\begin{array}{l}<5 \% \text { per } \\
\text { logarithmic } \\
\text { scale }\end{array}$ & $\begin{array}{c}<5 \% \text { per } \\
\text { logarithmic } \\
\text { scale }\end{array}$ \\
\hline Dynamic drift & $0.00005 \% \pm$ & Not reported & Not reported \\
\hline $\begin{array}{c}0.05 \mathrm{~Hz} \text { to } 0.5 \\
\mathrm{~Hz}\end{array}$ & $\begin{array}{c}0.00002 \text { after } 1 \\
\text { hour }\end{array}$ & & \\
\hline $\begin{array}{l}\text { Effect of drift on } \\
\text { hysteresis }\end{array}$ & $\begin{array}{l}\text { From } 8.37 \% \text { to } \\
19.48 \% \text { at } 10 \mathrm{~N} \\
\text { for } 1 \text { hour }\end{array}$ & Not reported & Not reported \\
\hline $\begin{array}{c}\text { Cost for } 1 \\
\text { sensor }\end{array}$ & ${ }^{\mathrm{a}} \$ 0.31$ & $\$ 5.95$ & $\$ 8.5$ \\
\hline
\end{tabular}
Sensors and Commercially AVAilable Ones

The same was calculated but for the maximum (6) and for the minimum (7) voltage value found within that five initial and last seconds of the test.

$$
\begin{aligned}
& \text { Drift error maximum dynamic load } \\
& =\left(\frac{\left(\max _{t=3695}^{t=3600} V_{N}\right)-\left(\max _{t=0}^{t=5} V_{N}\right)}{\left(\max _{t=0}^{t=5} V_{N}\right)}\right) 100 \\
& \text { Drift error minimum dynamic load } \\
& =\left(\frac{\left(\min _{t=3695}^{t=360} V_{N}\right)-\left(\min _{t=0}^{t=5} V_{N}\right)}{\left(\min _{t=0}^{t=5} V_{N}\right)}\right) 100
\end{aligned}
$$

Comparisons between the characteristics determined for these sensors and the nearest commercially available sensors are presented in Table VI. 


\section{Bespoke Sensor Implementation Guide}

Sensors can be manufactured following the process presented in this paper. Make the electronic circuit as shown in Fig. 3 with the data acquisition system of your preference. Then follow the instructions below in order to obtain the corresponding force in Newtons based on the force-voltage relationship provided in this paper.

These steps minimize the effect of manufacturing imperfections that lead to different voltage offset and resistivity under no loading between sensors that may look alike otherwise.

1) Determine the voltage offset $\left(V_{0}\right)$ when the sensor is unloaded.

2) Apply $10 \mathrm{~N}$ and take a note of the voltage, this will be the voltage at maximum applied force $\left(V_{\max }\right)$. Make sure the applied load falls only inside the sensing area. This is the area where you observe a change of $\mathrm{V}$ for a change of force.

3) Calculate the force using the modified equation of the force-voltage relationship determined in this paper that takes into account the transformation and normalization of the voltage (2).

\section{DISCUSSION}

Through static and dynamic tests performed this paper has reported hysteresis and drift errors in the voltage response of bespoke force sensors. We have also suggested a method of normalizing and removing the voltage offset of such bespoke sensors before determining a calibration curve through which the user will be able to then test and measure forces, knowing the hysteresis and drift expected from such bespoke sensor in advance.

Drift and hysteresis errors of the sensors presented are similar to those reported by manufacturers of commercially available force sensors (Table VI). Minimum hysteresis $(12.96 \% \pm 6.24)$ was observed when applying $0.1 \mathrm{~N}$ every second while maximum hysteresis $(18.03 \% \pm 6.29)$ was observed at $1 \mathrm{~N} / \mathrm{s}$. It can be inferred that the hysteresis error will be greater the faster the load is applied to these bespoke sensors.

In applications where loads are held for less than a minute these bespoke sensors offer minimal drift error $(<1 \%$, for loads between 8 and $10 \mathrm{~N}$ ). The greatest drift error during the static tests was observed for $1 \mathrm{~N}$ after a two hours test. High drift was observed increasing from less than $5 \%$ at one minute to less than $24 \%$ at 2 hours when applying a $1 \mathrm{~N}$ load. These bespoke sensors will display less drift error when used in settings where loads are greater than $8 \mathrm{~N}$ for longer periods of time.

The dynamic tests show minimal drift $(0.00005 \%)$ after 1 hour which supports the application of these sensors in settings where forces are applied at frequencies below $0.5 \mathrm{~Hz}$. No manufacturer of current commercially available sensors has reported on the combined effect of drift error on hysteresis error of the voltage response. Here we have seen the greatest effect of drift on hysteresis for the highest load applied $(10 \mathrm{~N})$. Hysteresis error increased from $8.37 \%$ to $19.48 \%$ when accounting for the drift error in the same test. The effect of drift on hysteresis is important as this error has to be taken into account in applications where loading/unloading and static loading events are present, such as in human movement (i.e. human interaction with assistive technology, orthoses, prostheses and exoskeletons [14]).

The sensors presented provide some advantages including: ability to be made in any shape, have the electronic connections at any chosen location within the sensor and be of any size [1], [2], [4]. It is possible to modify the force sensing range of the sensors by modifying the number of polymer composite layers used [8], [9]. In this study we used three layers in order to achieve a measurement of $10 \mathrm{~N}$ without saturating the voltage output. Circuitry is kept simple by using voltage dividers, without the need for operational amplifiers.

Conductive glue and some pastes based on carbon and silver, traditionally used only in electron microscopy and electronic circuit repair applications, can be used for cold soldering of components in tailored applications. It is also possible to make a bespoke conductive adhesive [15].

Another potential advantage to these polymer sensors is their ability to cover an irregular shape. Commercially available flexible force sensing resistors (FSR) come in a variety of sizes (circular $11.34 \mathrm{~mm} 2$ to rectangular 6,217.12 mm2) however these come in regular shapes only [16], [17]. For some applications, many sensors in a relatively small area would be required, usually ruling out the cheaper commercially available sensors which, although have a small active sensing area (e.g. smallest known commercially available sensing area of a FSR is $11.34 \mathrm{~mm} 2$ by Tekscan Inc.), often have large and stiff electrode connections with sensor-electrode interfaces that break when bending. Bespoke force sensors offer the opportunity of choosing the wiring location and materials such as conductive thread to replace stiff electrodes allowing a high degree of flexibility.

As commercial force sensors are relatively expensive, these bespoke sensors may provide an affordable solution. With the recent development of open source, and also inexpensive, hardware and software by Arduino [18], Raspberry Pi [19], Engduino [20] and LittleBits [21], the possibilities of creating a reliable and tailored wearable force sensing system are plentiful.

We have suggested a method of normalizing and removing the voltage offset of bespoke made sensors before determining a calibration curve through which the user will be able to then test and measure forces. Calibration of sensors is a vital step to perform a reliable measurement application [22]. By calibrating force sensors one removes the bias and imprecision of the measurement but this is only true for the conditions under which that calibration is performed for each individual sensor [23]. For instance, on a flat surface and under a maximum force of $10 \mathrm{~N}$. Static calibration of these sensors is feasible if taking into account the drift error as reported here. For the sensor to provide a reliable measurement we recommend that its shape and size are adapted such that it can be installed on a flat hard surface.

These sensors may become vital in designing/studying assistive technology and medical devices where their interaction forces with the human body are of interest. These sensors are 
not only limited to application with humans, but could also be used in research with animal biomechanics, robotics, testing medical devices in veterinary science, or any other application where the measurement of the force with errors within those reported here are of interest.

In future, the response of the sensor could be characterized when installed on curved surfaces and exposed to changes of temperature. The potential of using these sensors as bend sensors (modifying its current geometry into different shapes) should also be evaluated thoroughly.

\section{CONCLUSION}

We have chosen and tested conductive materials in order to build thin and flexible force sensors that can be fabricated in any shape and size and with the electrical wiring in any convenient location. A thorough voltage response characterization has shown that their hysteresis and drift errors are within those observed in commercially available force sensing resistors. The hysteresis error will be greater the faster the load is applied to these bespoke sensors. In applications where forces are held for less than a minute these bespoke sensors offer minimal drift error. These bespoke sensors will display less drift error when used in settings where loads are greater than $8 \mathrm{~N}$ for longer periods of time. A novel test was developed to account for combined hysteresis and drift errors that could be observed in applications where loading, unloading and continuous forces are present, such as in human biomechanics and human-computer interaction. We have provided a video fabrication guide and a written implementation guide to minimize the effect of manufacturing imperfections that lead to different voltage offset and resistivity between bespoke sensors that may look alike otherwise.

\section{APPENDIX}

A video depicting the manufacture of a force sensor with an irregular shape and a file with the response of each sensor is available in the Supplementary Material.

\section{ACKNOWLEDGMENT}

Eve Hatten (UCL Medical Physics and Biomedical Engineering Department), Adam Wojcik, Peter Kelly and Neil Collings (Mechanical Engineering UCL), and the Institute of Making (UCL).

\section{REFERENCES}

[1] M. Satomi and H. Perner-Wilson. (Jan. 15, 2016). KOBAKANT DIY Wearable Technology Documentation. How to Get What You Want-Stickytape Sensors. [Online]. Available: http://www.kobakant.at/ $\mathrm{DIY} / \mathrm{p}=429$

[2] (Jan. 15, 2015). Sensor Film Kit. [Online]. Available: http://www. sensorfilmkit.com/

[3] X. Lin and B. C. Seet, "A linear wide-range textile pressure sensor integrally embedded in regular fabric," IEEE Sensors J., vol. 15, no. 10, pp. 5384-5385, Oct. 2015.

[4] L. Buechley. (Jan. 16, 2016). MAS.962 Special Topics: New Textiles, Spring. [Online]. Available: http://ocw.mit.edu/courses/media-arts-andsciences/mas-962-special-topics-new-textiles-spring-2010/

[5] B. W. Lee and H. Shin, "Feasibility study of sitting posture monitoring based on piezoresistive conductive film-based flexible force sensor," IEEE Sensors J., vol. 16, no. 1, pp. 15-16, Jan. 2016.

[6] M. Salerno, "Safety systems in magnetically driven wireless capsule endoscopy," in Proc. IEEE/RSJ Int. Conf. Intell. Robots Syst., Nov. 2013, pp. 3090-3095.
[7] R. Horne, S. Kelly, and P. Sharp, "Resistopalatography as an assistive technology for users with spinal cord injuries," in Proc. 37th Annu. Int. Conf. IEEE Eng. Med. Biol. Soc. (EMBC), Aug. 2015, pp. 4367-4370.

[8] M. Kalantari, J. Dargahi, J. Kövecses, M. G. Mardasi, and S. Nouri, "A new approach for modeling piezoresistive force sensors based on semiconductive polymer composites," IEEE/ASME Trans. Mechatronics, vol. 17, no. 3, pp. 572-581, Jun. 2012.

[9] S. Salibindla, B. Ripoche, D. T. H. Lai, and S. Maas, "Characterization of a new flexible pressure sensor for body sensor networks," in Proc. IEEE 8th Int. Conf. Intell. Sensors, Sensor Netw. Inf. Process., 2013, pp. 27-31.

[10] L. Harris, "Design and fabrication of a piezoresistive fabric sensor for ergonomic analyses," M.Sc. thesis, Univ. Guelph, Faculty of Applied Sciences, Guelph, ON, Canada, 2014.

[11] C. B. Goy et al., "Design, fabrication and metrological evaluation of wearable pressure sensors," J. Med. Eng. Technol., vol. 39, no. 3, pp. 208-215, 2015.

[12] E. R. Komi, J. R. Roberts, and S. Rothberg, "Evaluation of thin, flexible sensors for time-resolved grip force measurement," in Proc. Inst. Mech. Eng., J. Mech. Eng. Sci., vol. 221, no. 12, pp. 1687-1699, 2008.

[13] E. O. Doebelin, "Generalized performance characteristics of instruments," in Measurement Systems: Application and Design. New York, NY, USA: McGraw-Hill, 2004, pp. 40-103.

[14] N. Jarrasse and G. Morel, "Connecting a Human Limb to an Exoskeleton," IEEE Trans. Robot., vol. 28, no. 3, pp. 697-709, Jun. 2012.

[15] (Jan. 16th, 2016). Make Conductive Glue and Glue a Circuit Mikey77. [Online]. Available: http://www.instructables.com/id/Make-ConductiveGlue-and-Glue-a-Circuit/

[16] Interlink Electronics. (Jan. 15, 2016). Standard Products-Force Sensing. [Online]. Available: http://interlinkelectronics.com/standardproducts.php

[17] Tekscan Inc. (Jan. 15, 2016). Force Measurement. [Online]. Available: http://www.tekscan.com/product-group/test-measurement/ force-measurement-tab=products-solutions

[18] (Jan. 7, 2016). Arduino. [Online]. Available: http://www.arduino.cc

[19] Raspberry Pi Foundation. (Jan. 7, 2016). Raspberry Pi-Teach, Learn, and Make With Raspberry Pi. [Online]. Available: www.raspberrypi.org

[20] University College London. (Jan. 7, 2016). Engduino. [Online]. Available: http://www.engduino.org

[21] Littlebits Electronics. (Jan. 7, 2016). Littlebits: Electronic Building Blocks for Creating Inventions Large and Small. [Online]. Available: http://littlebits.cc

[22] I. J. Busch-Vishniac, "Response characteristics," in Electromechanical Sensors and Actuators. New York, NY, USA: Springer, 1999, pp. 300-310.

[23] D. Ştefănescu, "Force sensing resistors (FSRs)," in Handbook of Force Transducers. Berlin, Germany: Springer-Verlagg, 2011, pp. 62-65.

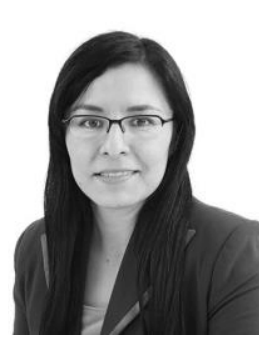

Dafne Zuleima Morgado Ramirez received the B.S. degree in biomedical engineering, the Postgraduate Diploma degree in rehabilitation engineering from Universidad Iberoamericana, Mexico City, the M.Sc. degree in biomedical engineering from the Queen Mary University of London, and the Ph.D. degree in biomechanics from the University of Roehampton in U.K. She was a Research Associate with the Institute of Orthopaedics and Musculoskeletal Science at the University College London, located at the Royal National Orthopaedics Hospital, Stanmore, U.K. She was part of a multidisciplinary team with a very ambitious project of creating an exoskeleton made of smart materials that could be worn below clothes and that could aid people with movement and sensing disabilities, such as with spinal cord injury patients. She helped in the fabrication of a physical human finger model, simulating skin and installing made to measure force sensors, and designing an automated right elbow exoskeleton for research purposes. She joined the Interaction Centre (UCLIC) at the University College London, where she is currently a Research Associate exploring the appropriateness and HCI opportunities of power assist devices for manual wheelchair users. Her research interests are HCI, biomechanics, biomedical instrumentation and signal processing, assistive and wearable technology, pets-HCI and product design. She is part of the community of the Global Disability Innovation Hub.

Dr. Morgado Ramirez has also worked in industry, providing preventive and corrective maintenance to laser-based medical equipment used in aesthetic skin treatments and also helping in research by improving the current delivery of laser through fiber-optic probes. 


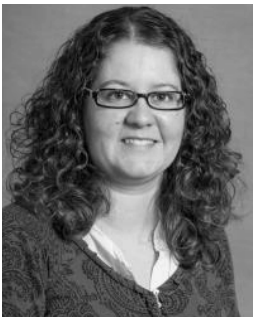

Maria del Pilar Garcia Souto received the B.Sc. degree in physics, majoring in electronics from the University of Santiago de Compostela, Spain, in 2003, the M.Sc. degree in information technologies, and the $\mathrm{Ph} . \mathrm{D}$. degree in biomedical engineering from Queen Mary, University of London, U.K., in 2012. She became a Fellow of the Higher Education Academy in 2013.

Since 2007, she has been combining research and teaching activities. She is currently a Senior Teaching Fellow with UCL Medical Physics and Biomedical Engineering Department, specifically in the IEP Biomedical Engineering Program.

Her research interests, matching her multi-disciplinary profile, include infrared technology, human thermoregulation and thermal comfort, image processing, product design and mechanical characterization of materials.

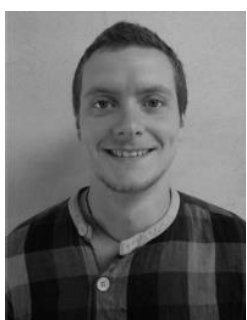

Benjamin. M. Oldfrey received the M.Phys. degree in physics from the University of Manchester in 2010, and the M.Res. degree in mathematical modeling of complex biological systems from University College London in 2014, where he is currently pursuing the Ph.D. degree in intelligent systems.

His research interests include the electrophysiology of the body from the molecular level to whole organ systems, novel exoskeleton devices, biomimetic electronic design, and direct multi-scale manufacturing of intelligent devices with a particular focus on skin.

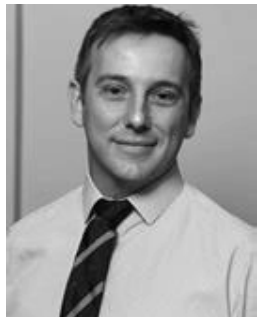

Peter Smitham studied medicine with the University of Bristol, U.K., and received the Ph.D. degree from the University of New South Wales, Australia. He completed his FRCS (Tr\&Orth) from the Royal College of Surgeons of England in 2015.

After completing his orthopedic surgical training with the Royal National Orthopaedic Hospital, Stanmore Rotation, U.K., he completed a Complex Revision Arthroplasty Fellowship with the Royal Adelaide Hospital, Australia and stayed for another year to complete a Trauma Fellowship. He is currently an Honorary Clinical Lecturer with University College London and the University of Adelaide.

Mr. Smitham was a recipient of the British Orthopaedic Research Society Travel Fellowship. He is past President of the British Orthopaedic Trainee Association.

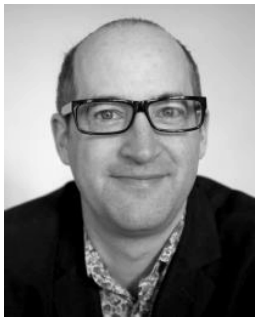

Mark Miodownik was born in London, U.K., in 1969. He received the B.A. (Hons.) degree in materials science and the Ph.D. degree in turbine jet engine alloys from Oxford University in 1992 and 1996, respectively.

$\mathrm{He}$ is currently a Professor of Materials and Society, UCL, where he teaches and runs a research group His current research interests are animate materials, innovative manufacturing, and sensoaesthetic materials. For more than ten years, he has championed materials research that links the arts and humanities to medicine, engineering, and materials science. This culminated in the establishment of the UCL Institute of Making, where he is Director and runs the research programme.

Prof. Miodownik was a recipient of the Royal Academy of Engineering Rooke Medal in 2013 and was elected Fellow of the Royal Academy of Engineering in 2014. He is the author of Stuff Matters, a New York Times Best Selling book, which won the Royal Society Winton Prize in 2014 and the U.S. National Academies Communication Award in 2015. In 2016, he was awarded the American Association for the Advancement of Science Prize for Public Engagement with Science.

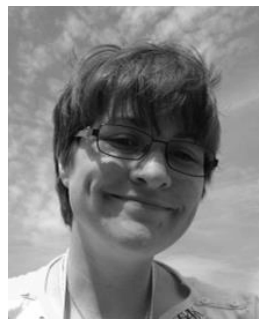

Catherine Holloway received the degree (First Class Hons.) in industrial engineering from the National University of Ireland, Galway, in 2004, and the Ph.D. degree from UCL in 2012. She is currently a Senior Lecturer with the Department of Computer Science, UCLIC, and the UCL Engineering Lead for the newly established Global Disability Innovation Hub. She is also passionate about the design of usable assistive technologies and making cities accessible. She is the CEO of Movement Metrics, a community interest company focused on transferring the latest research in embedded and connected sensor technologies in assistive devices to market. She directs the UCL-James Dyson Foundation Summer School each year on wheelchair design. 